\title{
The Long-Term Trend of Upper-Air Temperature in China Derived from Microwave Sounding Data and Its Comparison with Radiosonde Observations
}

\author{
YANJUN GUO \\ National Climate Center, China Meteorological Administration, Beijing, China \\ FUZHONG WENG \\ Laboratory of Severe Weather, Chinese Academy of Meteorological Sciences, Beijing, China \\ GUOFU WANG \\ National Climate Center, China Meteorological Administration, Beijing, China \\ WENHUI XU \\ National Meteorological Information Center, China Meteorological Administration, Beijing, China
}

(Manuscript received 3 October 2019, in final form 28 June 2020)

\begin{abstract}
Currently, the satellite Microwave Sounding Unit (MSU/AMSU) datasets developed from three organizations-Remote Sensing Systems (RSS), the University of Alabama at Huntsville (UAH), and the NOAA Center for Satellite Applications and Research (STAR) - are often used to monitor the global longterm trends of temperatures in the lower troposphere (TLT), midtroposphere (TMT), total troposphere (TTT), troposphere and stratosphere (TTS), and lower stratosphere (TLS). However, the trend in these temperatures over China has not been quantitatively assessed. In this study, the decadal variability and longterm trend of upper-air temperature during 1979-2018 from three MSU datasets are first evaluated over China and compared with the proxy MSU dataset simulated from homogenized surface and radiosonde profiles (EQU) at 113 stations in China. The regional mean MSU trends over China during 1979-2018 are $0.22-0.27$ (TLT), $0.15-0.22$ (TMT), 0.20-0.27 (TTT), 0.02-0.14 (TTS), and from -0.33 to -0.36 (TLS) $\mathrm{K}$ decade $^{-1}$, whereas the EQU trends are 0.31 (TLT), 0.19 (TMT), 0.24 (TTT), 0.07 (TTS), and -0.26 (TLS) $\mathrm{K} \mathrm{decade}^{-1}$. The trends from RSS generally show a better agreement with those from EQU. The trends from both MSU and EQU exhibit seasonal and regional difference with a larger warming in TLT in February and March, and stronger cooling in TLS from late winter to spring. The TLT and TMT over the Tibetan Plateau and northwestern China show larger warming trends. The variability from MSU and EQU agree well except TLT in Tibet and southern China. The major difference in regional mean temperatures over China between MSU and EQU is related primarily to the satellite instrument changes during 1979-98 and the radiosonde system changes in China in the 2000s.
\end{abstract}

\section{Introduction}

Upper-air temperature is one of the essential climate variables measuring the atmospheric state and its longterm trend is an important indicator for climate change. Generally, upper-air temperature data are obtained from satellite remote sensing and in situ radiosonde observations. Since 1978, NOAA has launched a series

Corresponding authors: Fuzhong Weng, wengfz@cma.gov.cn; Yanjun Guo,gyj@cma.gov.cn of satellites with the Microwave Sounding Unit (MSU) and the Advanced Microwave Sounding Unit (AMSU) onboard. MSU and AMSU measure the radiance of at the top of atmosphere at microwave frequencies from 23 to $60 \mathrm{GHz}$. These measurements are used to deduce the temperature of deep atmospheric layers. Since the 1950s, the upper-air pressure, temperature, and humidity have been measured by balloon-borne radiosondes that make measurements in situ and transmit to ground stations. Obviously, satellites and radiosondes are two distinct systems and have their own advantages and 
limitations. MSU/AMSU has a global coverage but is limited by a coarse vertical resolution and a shorter observation period while radiosondes recorded longer time series with a higher vertical resolution but are restricted by sparse spatial sampling. Since both satellite and radiosonde observations are designed primarily for weather applications, the discontinuities from the change of instruments are typically handled by the bias correction in data assimilation. For climate applications, the original temperatures from satellites and radiosondes have been homogenized by multiple organizations. For example, the fifth assessment of IPCC (2013) used three merged satellite MSU/AMSU temperature datasets from University of Alabama at Huntsville (UAH; Christy et al. 2003), Remote Sensing Systems (RSS; Mears et al. 2003; Mears and Wentz 2009a,b), and NOAA Center for Satellite Applications and Research (STAR; Zou and Wang 2011; Zou et al. 2006) and five global homogenized radiosonde datasets including Hadley Centre Radiosonde Temperature (HadAT; Thorne et al. 2005b), Radiosonde Atmospheric Temperature Products for Assessing Climate (RATPAC; Free et al. 2005); Radiosonde Observation Correction using Reanalysis (RAOBCORE; Haimberger 2007), Radiosonde Innovation Composite Homogenization (RICH; Haimberger et al. 2012), and Iterative Universal Kriging Radiosonde Analysis Project (IUK; Sherwood and Nishant 2015). Over the past two decades, a great number of studies have been made to compare the upper-air temperature changes from satellite MSU and radiosonde observations with a focus on the global scale (Hurrell et al. 2000; Randel and Wu 2006; Thorne et al. 2005a, 2011; Haimberger et al. 2008; Randall and Herman 2008; Mears et al. 2012; Po-Chedley and Fu 2012; PoChedley et al. 2015; Seidel et al. 2004, 2009, 2011; Christy and Norris 2006, 2009; Christy et al. 2007, 2018). The unanimous conclusion derived from satellite and radiosonde datasets is a warming trend in the troposphere and a cooling trend in stratosphere since the late twentieth century. However, there is a substantial disagreement in trend of extratropical troposphere over the Northern Hemisphere (IPCC 2013).

Given the complexity of the climatic system and the substantial disagreement of upper-air temperature change, it is our interest to focus on upper-air temperature in China and investigate the long-term trend and uncertainty at a regional scale as depicted by satellites and in situ data. Since the 1950s, China has established a geographically dense radiosonde network. Most of the previous studies on upper-air temperature change in China are based on radiosonde observations (Zhai and Eskridge 1996; Zhai 1997; Guo et al. 2008, 2016; Guo and Ding 2009, 2011; Chen and Yang 2014). Limited studies were also conducted on uses of satellite MSU earlier version dataset (Liao et al. 2011) and on comparison between MSU and radiosonde temperatures
(Guo et al. 2019). However, the accuracy of satellitederived trends over China has not been fully explored. Today, more and more satellites include microwave sounders onboard. These advanced instruments collect the atmospheric temperature information with better spatial and time resolutions and with a quality similar to and better than the early MSU data. Thus, MSU-like data records are now playing an increasingly important role in estimating the long-term trend and uncertainty of upper-air temperatures. It is necessary to apply the latest version of multiple satellite MSU datasets to thoroughly evaluate the long-term trend and uncertainty of upper-air temperature over China, and to compare with in situ temperatures at individual stations. The trend differences between MSU and radiosonde data can be better understood by examining the details of radiosonde metadata at regional scales or individual stations over China.

In this study, section 2 describes the details of datasets of satellite MSU and conventional observations and the method we use to convert radiosonde profiles to equivalent MSU measurements, and compares the impacts of different samplings over China. Section 3 presents the regional mean time series in China from MSU and radiosonde equivalents during 1979-2018 and the response to ENSO and volcanic eruptions. Specifically, the long-term variability of trend and its seasonal and regional feature are evaluated to understand the change of trends. The upper-air temperatures over China derived from satellite MSU and radiosonde equivalents are compared through various statistical parameters. Temperature anomalies at four stations are analyzed with metadata records and merging information for a better understanding of the difference between MSU measurements and radiosonde equivalents. Section 4 summarizes the major conclusions from this study.

\section{Data and methodology}

\section{a. Data}

The satellite MSU/AMSU data used in this study are the latest versions of the monthly mean layer temperature datasets from RSS, UAH, and STAR. The RSS 4.0 (Mears and Wentz 2016, 2017) includes temperature of the lower troposphere (TLT), middle troposphere (TMT), total troposphere (TTT), and lower stratosphere (TLS) during 1979-2018, and temperature of the troposphere and stratosphere (TTS) during 1987-2018. TTT is a linear combination of TMT and TLS to reduce the influence of the lower stratosphere by using TTT $=1.1 \times \mathrm{TMT}-0.1 \times$ TLS, proposed by Fu and Johanson (2005) (http://www. remss.com/measurements/upper-air-temperature/). The 


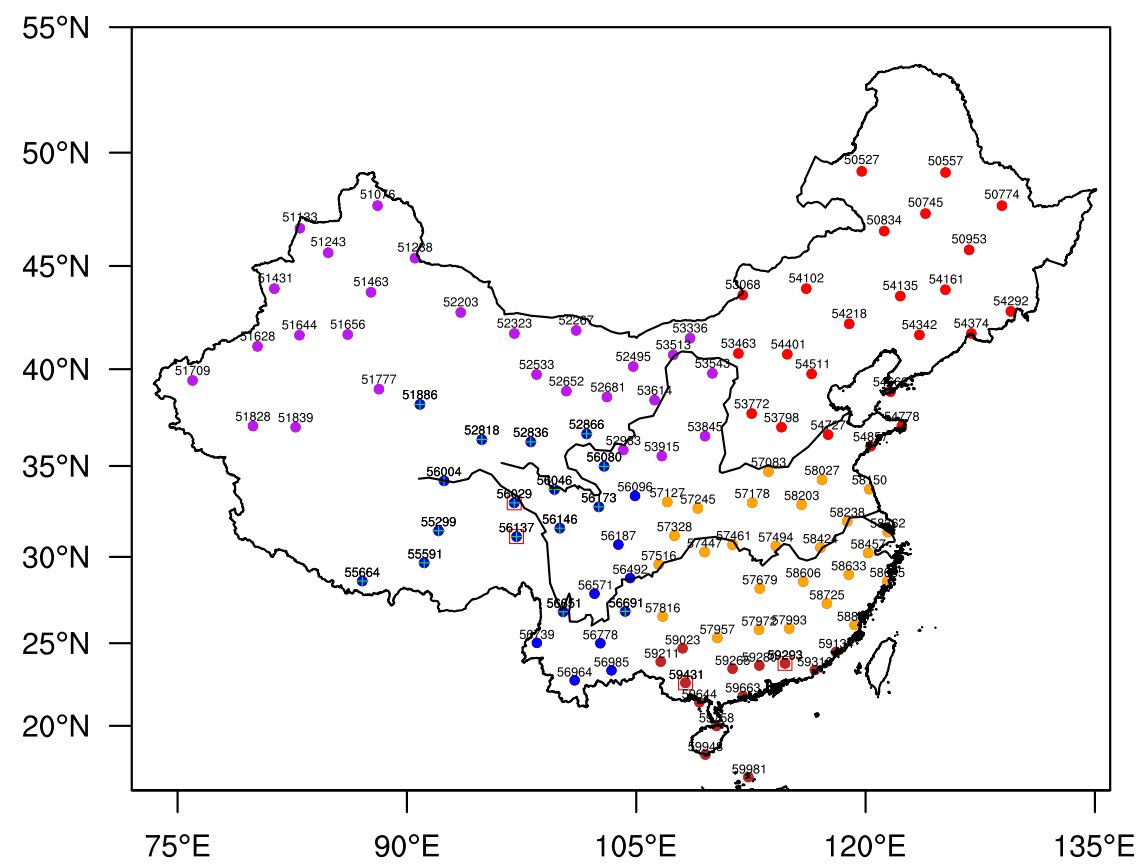

FIG. 1. Distribution of 113 radiosonde stations in China. The colored dots are the locations of the radiosonde stations and five colors represent five subregions $(1=$ red, $2=$ orange, $3=$ brown, $4=$ purple, $5=$ dark blue), the green crosses are the locations of stations with a surface elevation above $2000 \mathrm{~m}$, and the larger red squares are a representative station. Station numbers are given above the colored dots.

UAH 6.0 (Spencer et al. 2017) includes TLT, TMT, TTT, TLS, and temperature of the tropopause (TTP) during 1979-2018, which have substantial improvements in methods and procedures from previous versions, including a new multichannel for TLT computing and an empirical method for diurnal drift correction. The STAR 4.0 (Zou and Qian 2016; Zou et al. 2018) includes TMT, TTT, and TLS during 1979-2018 and temperature of the upper troposphere (TUT) during 1981-2018. TTS from RSS, TTP from UAH, and TUT from STAR are hereinafter collectively referred to as TTS. The climatology of temperature is based on a common period of 1981-2010 with the exception of TTS, which has a base period of 1987-2010.

The in situ data are homogenized monthly surface temperatures and air humidity (Xu et al. 2019; Cao et al. 2016) and temperature at 10 mandatory levels $(850,700$, 500, 400, 300, 200, 150, 100, 50, and $30 \mathrm{hPa}$ ) (Chen and Yang 2014; Guo and Wang 2019; Zhang et al. 2018) over China during 1979-2018. It should be pointed out that the number of levels in radiosonde profiles is not always 10 , depending on the altitude of individual stations. At the high-altitude stations, the first mandatory level above the surface is 700 or $500 \mathrm{hPa}$. The set of 113 stations with data availability above $70 \%$ (Guo and Ding 2009) is shown in Fig. 1 and selected for this research.
The regional features of upper-air temperature trend in China are classified into five subregions according to their climate zone (see distribution in Fig. 1). Subregion 1 is northeastern and North China, subregion 2 is the Yangtze River reaches, subregion 3 is southern China, subregion 4 is northwestern China, and subregion 5 is southwestern China. In addition, the grids with station elevations above $2000 \mathrm{~m}$ in the Tibetan Plateau are defined as subregion 6 (light blue cross in Fig. 1) for better understanding of upper-air temperature change in highaltitude areas. Temperature trends in the six subregions are studied in section $3 \mathrm{~d}$.

\section{b. Methodology}

The anomalies of layer mean temperature are analyzed to understand the variability and long-term trend during 1979-2018 at regional mean or grids (stations) over China. Temperatures from MSU (RSS, UAH, and STAR) and in situ simulations (EQU) are compared in terms of correlation, ratio of standard deviation (RSD), and root-mean-square deviation of difference (RMSD) to understand the consistency or difference from each other. The linear trends are obtained by the least-squared method. RSD and correlation represent difference or similarity in variation. A correlation or RSD value close to 1 or RMSD value 
TABLE 1. Statistical comparisons of monthly layer temperature anomalies averaged over China with four different samplings $(\mathrm{Cn}$, sta, nosta, and 2000+) during 1979-2018 from RSS.

\begin{tabular}{lllllll}
\hline \hline Statistics & Samplings & TLT & TMT & TTT & TTS & TLS \\
\hline Correlation & Cn, sta & 0.97 & 0.98 & 0.98 & 0.99 & 0.99 \\
& Cn, nosta & 0.97 & 0.97 & 0.97 & 0.99 & 0.99 \\
\multirow{4}{*}{ RMSD } & Cn, 2000+ & 0.69 & 0.79 & 0.81 & 0.92 & 0.93 \\
& Cn - sta & 0.17 & 0.12 & 0.14 & 0.06 & 0.15 \\
& Cn - nosta & 0.18 & 0.12 & 0.14 & 0.07 & 0.16 \\
RSD & Cn - 2000+ & 0.81 & 0.50 & 0.58 & 0.18 & 0.41 \\
& sta/Cn & 0.96 & 0.98 & 0.99 & 0.92 & 0.98 \\
& nosta/Cn & 1.06 & 1.04 & 1.03 & 1.09 & 1.04 \\
& 2000+/Cn & 1.46 & 1.50 & 1.50 & 1.03 & 1.11 \\
\hline
\end{tabular}

close to 0 reflects a higher similarity between MSU and EQU.

\section{1) CONVERT THE RADIOSONDE PROFILES TO} BRIGHTNESS TEMPERATURES BY RTTOV

To compare the layer mean and gridded satellite brightness temperature with in situ observations, the Radiative Transfer for TOVS (RTTOV) v12 model (Saunders et al. 2018) is used to compute the brightness temperature at MSU channels from radiosonde profiles. Our simulated brightness temperatures from radiosondes are named MSU layer temperature equivalents (or EQU for simplicity).

The input data for RTTOV include monthly surface temperature and air humidity and temperature at 10 mandatory levels $(850,700,500,400,300,200,150,100$, 50 , and $30 \mathrm{hPa}$ ), which are the most complete homogenized data available in China. Before the radiative transfer simulations, the missing data of radiosonde profile are replaced by the climatology to ensure the temporal and spatial compatibility.

In radiative transfer simulations, the temperatures at the RTTOV levels are interpolated from radiosonde profiles. Since RTTOV model top reaches to $0.01 \mathrm{hPa}$, the climatological profiles above the radiosonde tops are also used for interpolation. The temperature profiles in RTTOV with 100 levels interpolated from radiosondes have enough detail to warrant the simulation accuracy.

In radiative transfer simulations, surface emissivity is a critical parameter and required for RTTOV inputs. In this study, a Tool to Estimate Land Surface Emissivities at Microwave Frequencies (TELSEM) land emissivity data atlas is downloaded from the Numerical Weather Prediction Satellite Application Facility (NWP SAF) and the emissivity data at TELSEM AMSU data at channel 3 (frequency $50.3 \mathrm{GHz}$ ) are utilized as an approximation to MSU emissivity.

\section{2) THE ALGORITHM FOR REGIONAL MEAN TIME SERIES OVER CHINA}

Since MSU is gridded data and covers all the regions, a comparison between satellite and radiosonde should be made at the collocated MSU grid cell and corresponding stations. Thus, subsampling is important in making a fair comparison between the spatially complete satellite MSU data and spatially incomplete radiosonde data. Previous studies have shown that different spatial samplings have a significant impact on the regional average time series at global or hemispheric scales and sampling effects dominate on small space and time scales (Hurrell et al. 2000; Free et al. 2005; Haimberger et al. 2008; Mears et al. 2011). However, the sampling impact on the regional mean time series over China has not yet been studied. Since the1950s, China has had its own dense radiosonde network. About 120 stations are widely distributed throughout the entire country and provide measurements over the complicated topography. For example, 16 stations are higher than $2000 \mathrm{~m}$ (green cross in Fig. 1) and cover the Tibetan Plateau where the average elevation is higher than $4000 \mathrm{~m}$. The MSU regional mean temperatures over China are quantitatively compared in four distribution samplings including all the grids in China, grids with stations, grids without stations, and grids with station elevations above $2000 \mathrm{~m}$. The first three samplings are all over the country and the last one is only in the Tibetan Plateau. Hereinafter these are referred to as $\mathrm{Cn}$, sta, nosta, and $2000+$, respectively.

The statistics of first three samplings show an excellent agreement with a significantly positive correlation among three datasets (0.97-0.99), small RMSD (0.06$0.18)$, and RSD close to 1 (0.92-1.09), while the statistical properties from the sampling $2000+$ exhibit a larger difference in TLT, TMT, and TTT with a much lower correlation (0.69-0.79) and larger RMSD (0.50-0.81) and RSD (1.46-1.50) (see Table 1).

As shown in Fig. 2, temperature anomalies averaged over China in four samplings show a similar variation, while the amplitudes of TLT, TMT, and TTT are obviously larger in $2000+$. Similarly, the amplitude of difference between $\mathrm{Cn}$ and $2000+$ is obviously larger than for other samplings, especially for TLT. The larger fluctuation of TLT anomaly and difference from 2000+ is associated with the high elevation and complex topography in the Tibetan Plateau. In addition, the diurnal adjustment is another factor causing the uncertainty since both TLT and TMT have significant surface contribution (Mears et al. 2011; Spencer et al. 2017), particularly over the Tibetan Plateau. Therefore, the impact of sampling on regional mean temperature over China is not as significant as on hemispheric or global average for a denser radiosonde network over China. However, MSU temperature over the Tibetan Plateau has fluctuatations of larger amplitudes than other regions in China, especially in TLT. To ensure better 



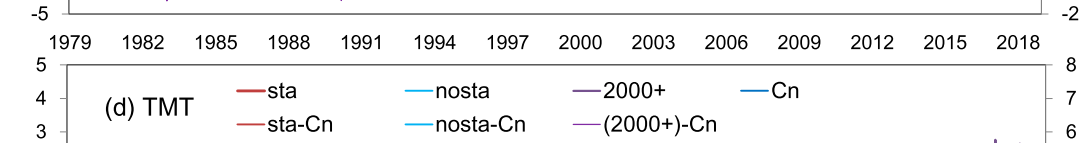
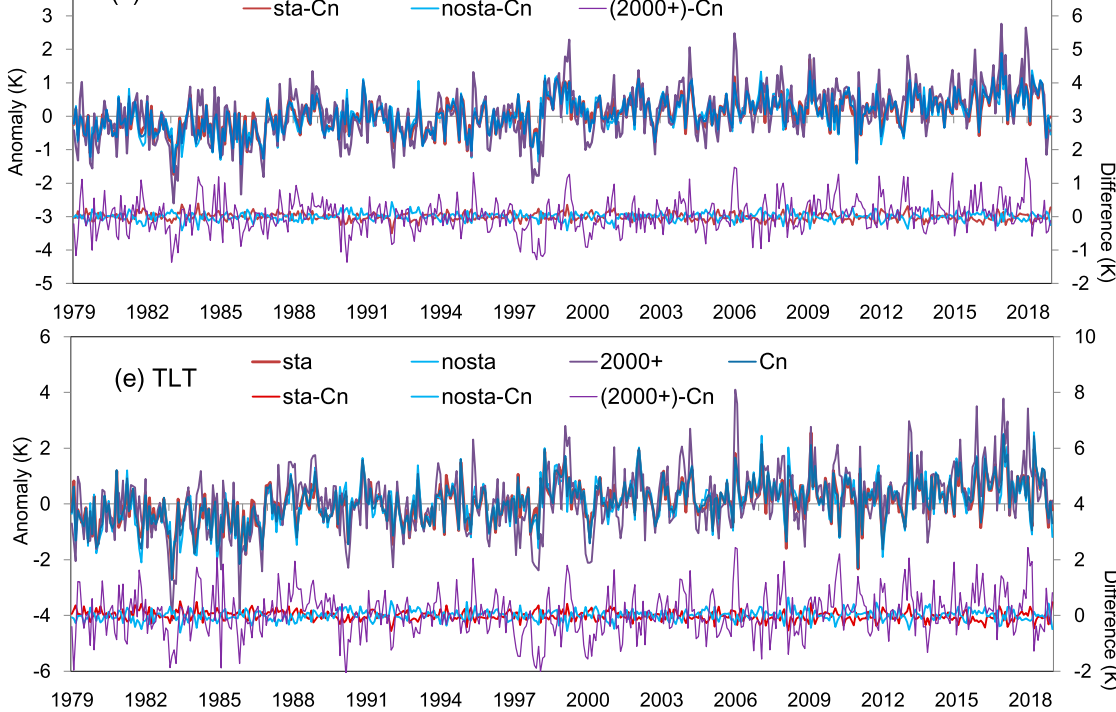

FIG. 2. Monthly temperature anomalies (K) averaged over China by different samplings (Cn, sta, nosta, and 2000+) during 1979-2018 from RSS and the difference with respect to Cn: (a) TLS, (b) TTS, (c) TTT, (d) TMT, and (e) TLT. For clarity, the difference time series are offset vertically. 
TABLE 2. Statistical comparisons of layer mean temperature anomalies averaged over China by sampling sta between MSU (RSS, UAH, and STAR) and EQU during 1979-2018.

\begin{tabular}{llccccc}
\hline \hline Statistics & Datasets & TLT & TMT & TTT & TTS & TLS \\
\hline Correlation & RSS & 0.90 & 0.97 & 0.98 & 0.92 & 0.96 \\
& UAH & 0.81 & 0.96 & 0.96 & 0.94 & 0.96 \\
\multirow{4}{*}{ RMSD } & STAR & - & 0.97 & 0.98 & 0.93 & 0.96 \\
& RSS & 0.32 & 0.12 & 0.13 & 0.15 & 0.27 \\
& UAH & 0.43 & 0.14 & 0.16 & 0.13 & 0.28 \\
RSD & STAR & - & 0.12 & 0.13 & 0.14 & 0.30 \\
& RSS & 1.00 & 1.03 & 1.04 & 0.96 & 1.07 \\
& UAH & 0.90 & 0.95 & 0.97 & 0.94 & 1.09 \\
& STAR & - & 1.04 & 1.05 & 0.99 & 1.08 \\
\hline
\end{tabular}

comparability, we perform an area-weighted average on the regional MSU temperature China by 113 stations or corresponding grids (i.e., sampling sta) in the following discussions.

\section{Analysis of variability and trend of atmospheric temperature in China}

\section{a. Temperature anomaly time series averaged over China from MSU and EQU}

Table 2 and Fig. 3 present statistical comparisons of temperature anomalies averaged over China during 1979-2018 from MSU (RSS, UAH, and STAR) and radiosonde equivalent (EQU). Generally, all MSU datasets show a good agreement and similar variability with EQU with a significant positive correlation (0.81$0.98)$, RSD close to 1 (0.90-1.09), and small RMSD (0.12-0.43). Among five layers, TLT shows more discrepancies with a lower correlation and higher RMSD. This is due to problems in both the satellite and radiosonde data. For satellite, the construction of TLT is done by weighted differences between MSU2 (or AMSU5) measurements and the differencing procedure can introduce some additional noise and increase the uncertainties (Mears and Wentz 2009b, 2017; Spencer and Christy 1992; Spencer et al. 2017). For both MSU and AMSU, weighted averages of measurements made at different Earth incidence angles are combined to produce a retrieval that is more sensitive to TLT than the simple unweighted radiances for the same channel. The view-differencing method used to create TLT leads to spatial smearing that causes large uncertainties in area having variable topography. In addition, because of larger surface contribution, the diurnal adjustment of TLT for drifting satellite measurement times is larger than for other layers, which lead to larger uncertainty (Mears and Wentz 2009b, 2017; Mears et al. 2011; Spencer et al. 2017). The anomaly difference with EQU in China shows larger discrepancies between MSU and
EQU in the 1980s and 2000s, which are mainly associated with the artificial changes of satellite instruments, surface, and radiosonde system. For the satellite systems during the 1980s and the early 1990s, the life expectancy of satellites from NOAA-6 to NOAA-12 is generally shorter and in consequence leads to larger uncertainties in merging the overlapping time series and removal of residual intersatellite bias. Figure 4 shows the average difference between MSU and EQU in the periods of each satellite (Mears and Wentz 2017). Taking TLT as an example, the amplitudes of difference in the periods from TIROS-N to NOAA-12 are obviously larger than other periods. In addition, the difference from RSS and UAH shows obvious inconsistency with opposite signs or large difference in the 1980s. The fluctuation of average difference is obviously larger in the mid-1980s when the periods for $N O A A-6, N O A A-9$, and $N O A A$ 10 overlapped, which may confirm the earlier finding on NOAA-9 calibration problems (Mears and Wentz 2009b; Po-Chedley and Fu 2012). By comparison of anomaly and difference, the major discrepancies in 1983, 1985, 1986, 1988, and 1991 coincided well with the launch time of the NOAA-8, NOAA-9, NOAA-10, $N O A A-11$, and $N O A A-12$ satellites, respectively, and the discrepancies among MSU datasets are obviously larger than those between any individual MSU dataset and EQU. Considering there is no nationwide and major system change during 1979-98 for radiosonde and surface observation in China, the significant jump of average difference and obvious inconsistency among MSU datasets indicate larger uncertainty in MSU during 1979-98, especially for TLT. For the radiosonde equivalents, uncertainty is mainly related to the discontinuities in surface and radiosonde temperature caused by nonclimate factors, such as an observation system upgrade, changes in instrument and practice, and a relocation of stations during the 2000s (Guo et al. 2019; Xu et al. 2019). The radiosonde network in China upgraded during 1999-2001 and the instrument changed from GZZ2 to GTS1 (L-band) during 2002-10 at most stations over China (Chen and Yang 2014; Guo et al. 2019). Surface observation was upgraded in 2000s from manually operated to automatic systems (Xu et al. 2019). These systematic changes inevitably lead to discontinuities and different adjustments from multiple research teams can cause discrepancies in temperature time series from MSU and EQU. The changes of radiosonde system in China during the 2000s result in some obvious discontinuities in EQU whereas MSU datasets show a better consistency. These results indicate the discrepancies in the 1980s and the 1990s are related to satellite system changes, whereas the discrepancies in the 2000 s are related to radiosonde system changes in China (Guo 

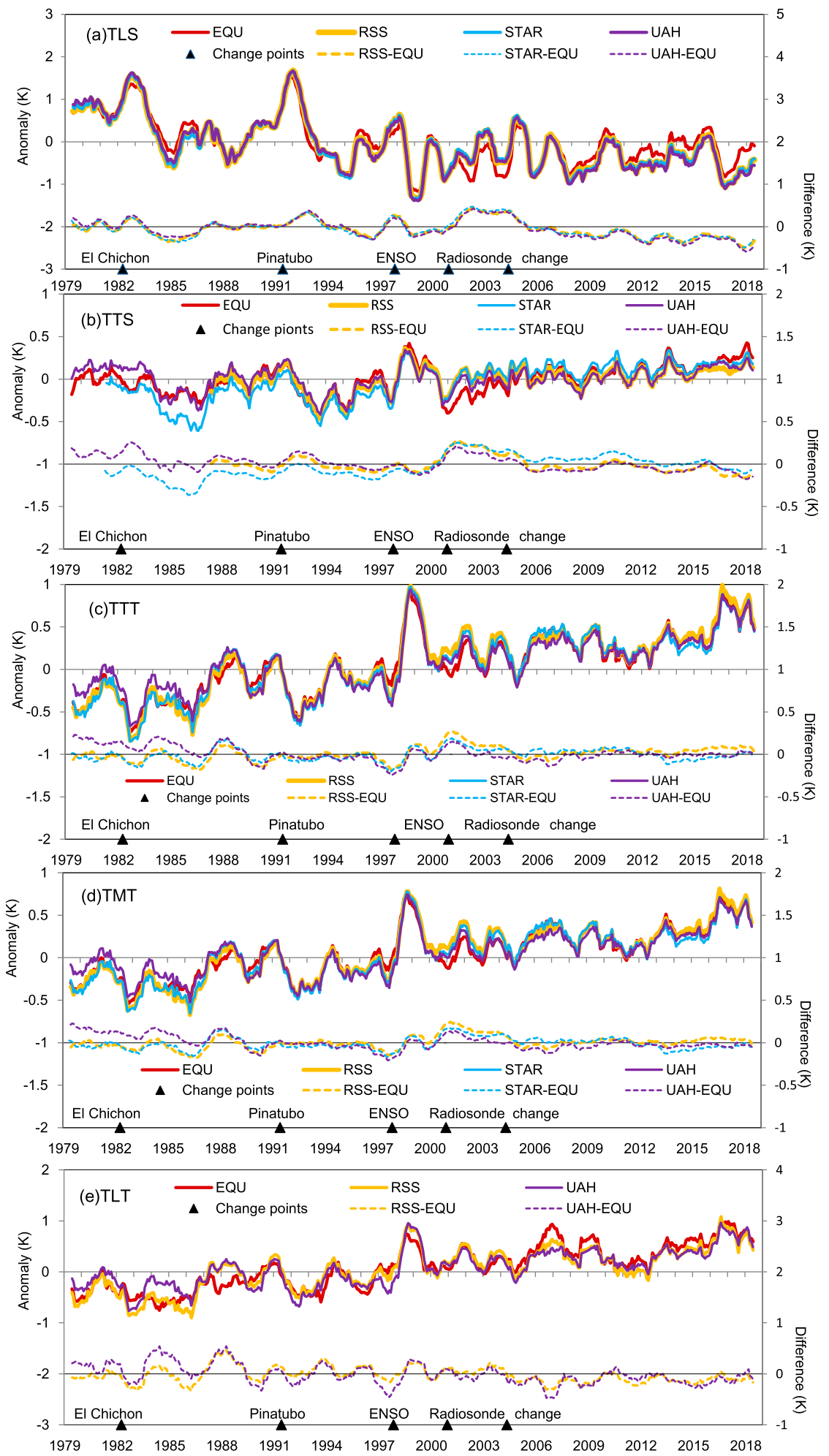

FIG. 3. The 12-month moving average temperature anomalies averaged over China by a sampling of Cn-sta from MSU (RSS, UAH, and STAR) and radiosonde (EQU) and difference with EQU from RSS, UAH, and STAR during 1979-2018: (a) TLS, (b) TTS, (c) TTT, (d) TMT, and (e) TLT. For clarity, the difference time series are offset vertically. (The black triangles represent the volcanic eruptions in 1982 and 1991, the strong ENSO event from 1997 to 1998 , the radiosonde system upgrade in China from 1999 to 2001, and the radiosonde instrument replacement at stations from 2002 to 2010.) 


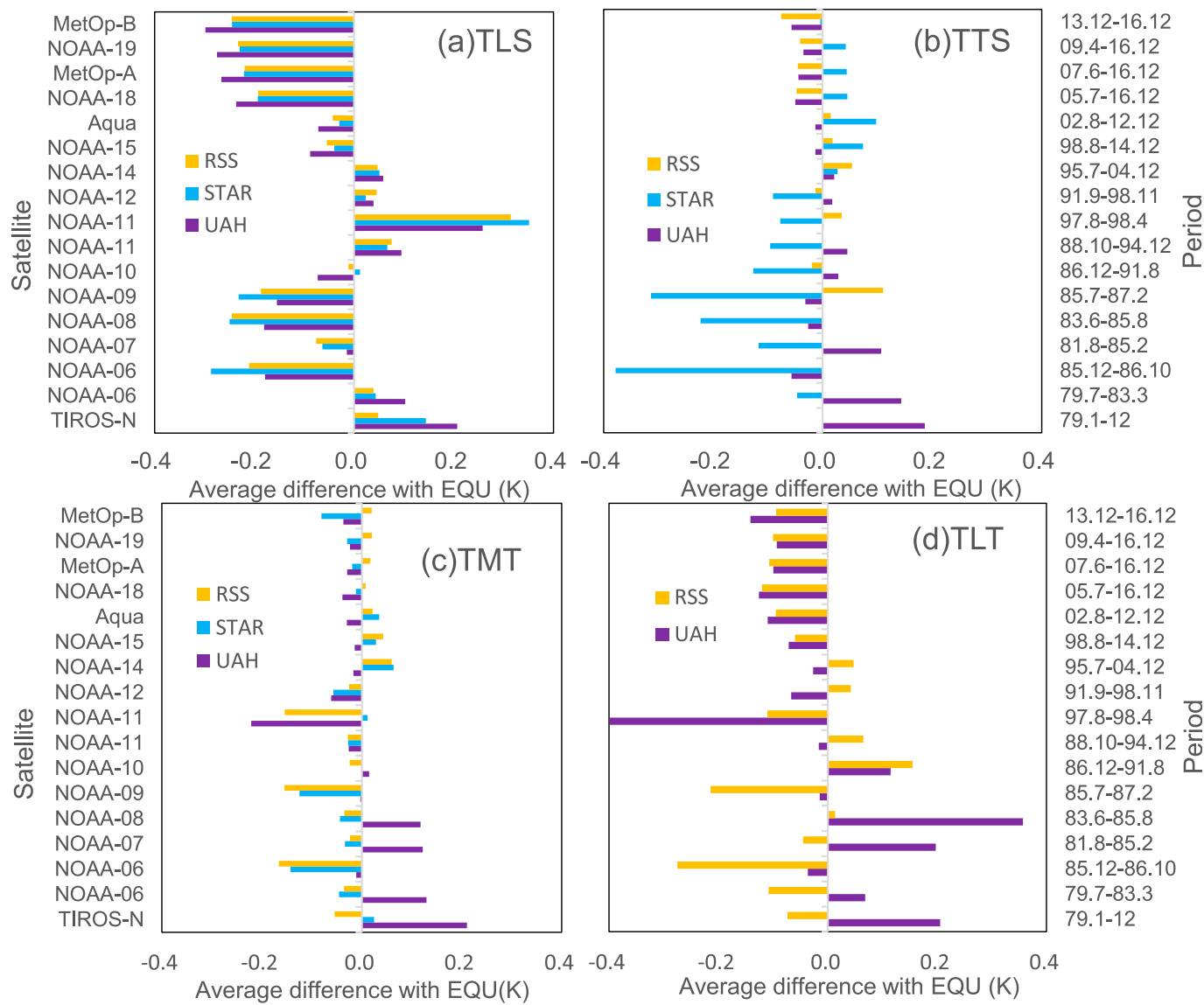

FIG. 4. Average of difference (K) between MSU (RSS, STAR, and UAH) and EQU in China by sampling sta during the periods for each satellite: (a) TLS, (b) TTS, (c) TMT, and (d) TLT. [The information about satellite and period is from Mears and Wentz (2017).]

et al. 2019). A mutual verification between satellite and radiosonde data is effective to identify the systematic bias caused by merging time series from different satellite or homogenization of original radiosonde time series and therefore improves the reliability and accuracy of upper-air temperatures made from the integrated observing systems.

For quantitatively measuring the response of layer mean temperature anomalies averaged over China to strong ENSO during 1997/98 and two major volcanic eruptions in 1982 and 1991, we apply the difference in average temperature anomaly in the 24 months following minus the 24 months preceding an ENSO event or each eruption (Seidel et al. 2004). As shown in Fig. 5, the differences from MSU and EQU show a consistency in all the layers with similar magnitudes. The response of temperature for ENSO is positive anomaly in troposphere and negative in lower stratosphere. The magnitudes in TLT, TTT, TMT, and TTS are $0.71-0.75,0.52-$ $0.63,0.52-0.54$, and $0.13-0.22 \mathrm{~K}$, respectively, while those in TLS are from -0.33 to $-0.47 \mathrm{~K}$. The response of temperature to the volcanic eruption is opposite to the ENSO, with a positive anomaly in the lower stratosphere and a negative anomaly in troposphere from MSU and EQU.

\section{b. Trends of layer temperature anomalies averaged over China}

Figure 6a shows the trends of layer temperature anomalies averaged over China during 1979-2018 from MSU and EQU. In general, the trend in troposphere is warming and that in lower stratosphere is cooling. The magnitudes of trends vary with layers and datasets. The range of warming trends from MSU is $0.22-0.27$ (TLT), 0.15-0.22 (TMT), 0.20-0.27 (TTT), and 0.02-0.14 (TTS) $\mathrm{K} \mathrm{decade}^{-1}$, and the cooling trends from MSU are from -0.33 to -0.36 (TLS) $\mathrm{K}$ decade $^{-1}$. While the warming trend from EQU in TLT $\left(0.31 \mathrm{~K} \mathrm{decade}^{-1}\right)$ is stronger and the cooling trend in TLS $\left(-0.26 \mathrm{~K} \mathrm{decade}^{-1}\right)$ is weaker than those from MSU, the warming trends in 

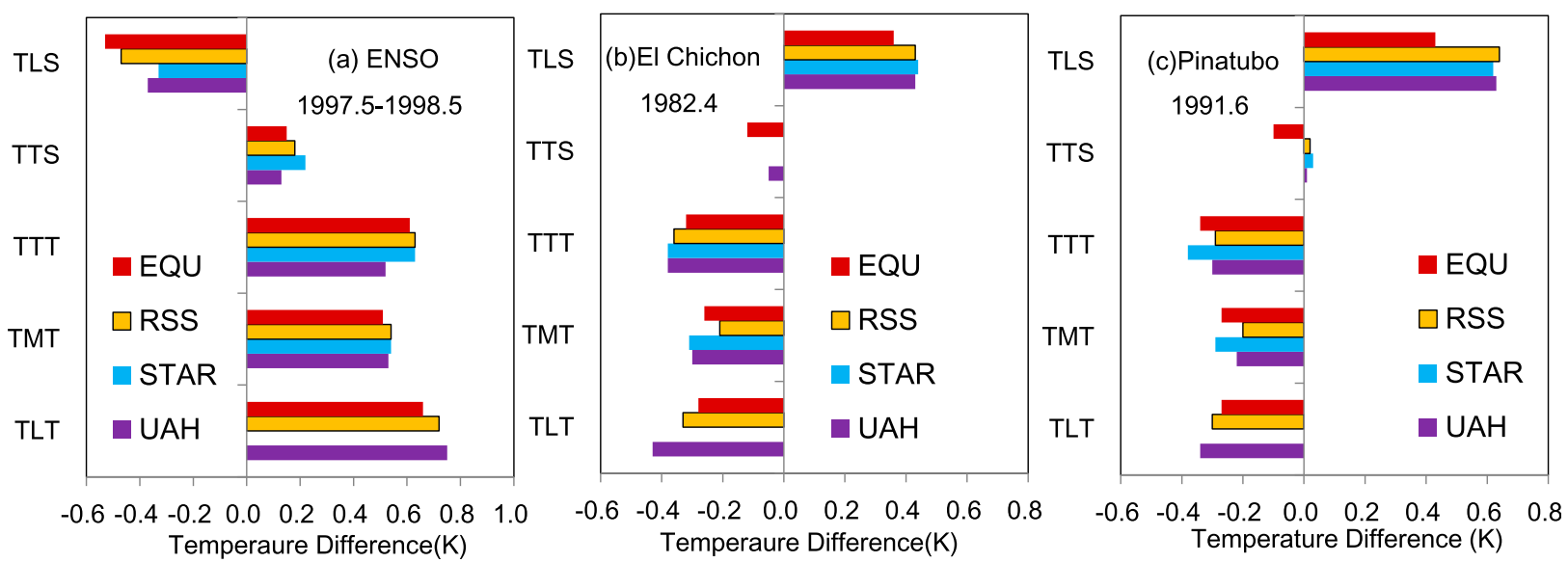

FIG. 5. The response of regional mean layer temperature $(\mathrm{K})$ averaged over China to strong ENSO and major volcanic eruptions:

(a) ENSO in 1997/98, (b) El Chichon in 1982, and (c) Pinatubo in 1991.

TMT, TTT, and TTS from EQU are in the range of trends from MSU. A larger warming trend in TLT from EQU than that from MSU is related to the significant difference in the 1980s between EQU and MSU. The larger difference of TLT anomaly and trend between RSS and UAH indicates a larger uncertainty in MSU. A weaker cooling trend in TLS from EQU than that from MSU may be due to the uses of climatological profiles in EQU simulations. The trends from UAH are less warming in troposphere and more cooling in TLS whereas those from STAR are opposite. Generally, RSS shows a better agreement with EQU than UAH and STAR.

Considering the trends are highly variable with selections of the beginning or ending years, frequent changes of satellite system that occurred before 1999, and radiosonde system changes over China that occurred during 1999-2010, we further divide the period of 1979-2018 into 1979-98 and 1999-2018 for a better understanding of the decadal-scale variability trends. As shown in Figs. $6 \mathrm{~b}$ and $6 \mathrm{c}$, the vertical structure of trends in atmosphere during different periods from all datasets reveals the stepwise change of temperature anomalies. The warming trends in TLT, TMT, and TTT during 1979-98 are stronger than the period 1999-2018 from RSS, STAR, and EQU. The flat TTS trends during 1979-98 are followed by a larger warming in 1999-2018 from all MSU and EQU. During 1999-2018, the TLS cooling trends from MSU dramatically decline whereas the TLS trend from EQU turns to a weak warming.

The warming trends in troposphere and cooling trends in lower stratosphere over China during 1979-2018 are associated with an increase of greenhouse gas amounts


FIG. 6. Vertical structure of linear trends $\left(\mathrm{K} \mathrm{decade}^{-1}\right)$ of layer temperature anomalies averaged over China for different periods from RSS, UAH, STAR, and EQU. The superimposed lines on the trends are uncertainties at the 95\% significance level. (a) 1979-2018, (b) 1979-98, and (c) 1999-2018. 
(a) $1979-2018$

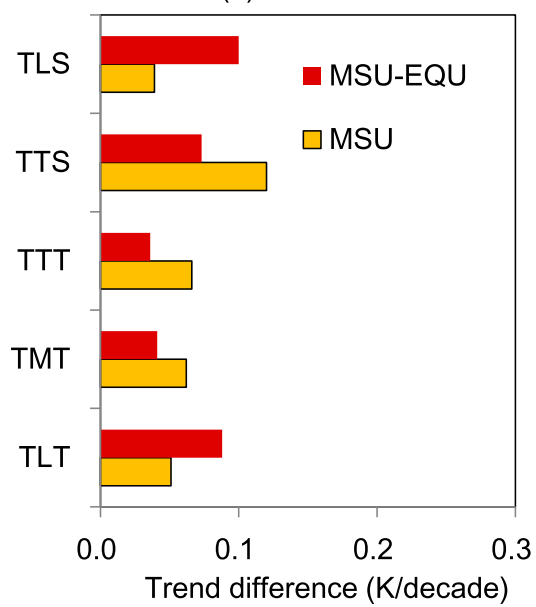

(b) $1979-1998$



(c) $1999-2018$



FIG. 7. Absolute value of maximum trend difference during different periods between individual MSU and EQU (red bar) or among the MSU datasets (orange bar) during (a) 1979-2018, (b)1979-98, and (c) 1999-2018.

in the troposphere and the ozone depletion in the stratosphere (Randel and Wu 1999; Hu and Tung 2003). The larger warming trends in troposphere over China during 1979-98 are attributed to impact of the strong El Niño from May 1997 to May 1998, for the common peaks around 1998 in TLT, TMT, TTT, and TTS anomalies averaged over China from all MSU and EQU (see Figs. 3b-e). According to the response of anomaly, the impact of 1997/98 ENSO on the trend is a larger warming in the troposphere $(0.18,0.15,0.13$, and $0.04 \mathrm{~K} \mathrm{decade}^{-1}$ in TLT, TTT, TMT, and TTS, respectively) and more cooling in TLS (about $-0.10 \mathrm{~K}$ decade $^{-1}$ ) during 1979-2018. Similarly, the impact of volcanic eruptions in 1981 and 1992 on trend is less cooling $\left(0.12 \mathrm{~K} \mathrm{decade}^{-1}\right)$ in TLS and less warming in tropospheric trends $(-0.09,-0.08,-0.06$, and $-0.01 \mathrm{~K}_{\text {decade }}{ }^{-1}$ in TTT, TLT, TMT, and TTS, respectively) during 1979-2018. The corresponding contributions of 1997/98 ENSO and two major volcanic eruptions in 1991 and 1982 are more significant to the trends during 197998 than the trends in the entire period. The cooling trends in TLS during 1979-98 are stronger than the whole period, which is due to a marked decline in the total ozone column from 1979 to the middle 1990s. The lowest annual mean total ozone columns occurred in 1992 in the Northern Hemisphere and as a result of enhanced ozone destruction linked to heterogeneous chemistry on volcanic aerosols and transport changes (Chipperfield et al. 2017). Major volcanic eruptions of the Mount Pinatubo in 1991 and El Chichon in 1982 caused an obvious increase of TLS. After each eruption, a significant decrease in TLS anomaly follows (see Fig. 3a). During 19992018, cooling trends in TLS from MSU dramatically decline and that from EQU shift to warming trend $\left(0.22 \mathrm{~K} \mathrm{decade}^{-1}\right)$. A significant decline of cooling trends in TLS and an increase of warming trends in TTS during 1999-2018 from both MSU and EQU match well with the ozone recovery period since the late 1990s.

For more accurately understanding the time-varying trend difference between MSU and EQU or among the MSU datasets, maximum absolute values of trend difference for each layer temperature are compared during three periods and are shown in Fig. 7. For simplicity, we refer to the trend difference among MSU datasets as MSU and the difference between MSU datasets and EQU as EQU. For the whole period (1979-2018), the magnitudes of trend difference between MSU and EQU are generally similar with those from MSU datasets. For the period of 1979-98, the magnitude of trend difference decreases with altitude and the MSU differences in TTS and TLS are larger than in EQU, which coincides with more frequent launches of satellites during 1979-98. On the contrary, there is no major system change in radiosonde observations over China, and the continuity of EQU during this period is better than MSU which is merged by multistage time series from NOAA-6 to NOAA-12. Therefore, the trend difference between EQU and MSU during 1979-98 is mainly related to the discontinuities caused by satellite system changes. For the period of 1999-2018, the magnitude of difference trend from MSU and EQU and its vertical difference are obviously larger than those from MSU. There are more frequent radiosonde system changes over China in the 2000s and more discontinuities, especially in TTS and TLS of EQU for solar radiation error, and the adjustment uncertainty is more significant in the upper troposphere and lower stratosphere (Guo et al. 2016, 2019). The warming trend in TLS EQU during 1999-2018 is 



FIG. 8. Five-year moving trend for difference with EQU averaged over China during 1979-2018 from RSS, UAH, and STAR: (a) TLS, (b) TTS, (c) TTT and TMT, and (d) TLT.

overestimated to some extent for residual discontinuity in 2000s. It is interesting to also see that the continuity of MSU during 1999-2018 is much better after AMSU-A onboard NOAA-15 replaced MSU in 1998. The long service period of NOAA-15 AMSU from 1998 to 2019 and a better calibration accuracy of AMSU data provide a better continuity in MSU time series. Therefore, the trend difference between EQU and MSU during 1999-2018 is mainly related to the discontinuities caused by the change in the Chinese radiosonde systems.

Moving trends of the differences between MSU and EQU can also illustrate the timing of differences (Randel and Wu 2006; Randall and Herman 2008; Mears et al. 2012). Five-year moving trends of layer temperature difference between MSU and EQU averaged over China during 1979-2018 are shown in Fig. 8 and the maximum and minimum represent the major changepoints of difference. The most significant points are the maximum during 1999-2001 and the minimum during 2003-06 in TLS, TTS, TTT, and TMT. The changepoints matched well with the radiosonde observation system upgrade and instrument mode replacement in the 2000s over China. These two changepoints are not obvious in TLT, which is reasonable, because the effect of radiosonde system change and homogenization on TLT is less than that on TMT, TTT, TTS, and TLS. The other major changepoints in 1983-84, 1986, 1989, 1991, and 1994-95 are associated with launch time of different satellites used in the merged MSU time series (NOAA-8, NOAA-10, NOAA-11, NOAA-12, and NOAA-14); meanwhile, there is no radiosonde system change over China. A high consistency in TLS, TTS,
TTT, and TMT among three MSU datasets indirectly indicates that the difference is likely caused by satellite system change, which confirms the results from trend difference during three periods. The moving trend of the difference shows more discrepancies between UAH and RSS in TLT and indicates a larger uncertainty in MSU, which is consistent with the comparison of regional mean anomalies. Moving trends of the differences at individual stations in China show a similar feature that confirmed with the exact timing record in the metadata (Guo et al. 2019).

Through a comparison of trend difference during three periods and the moving trend of difference during 1979-2018, we can infer that the main factors causing the discrepancies in trends are satellite and radiosonde system change, which is consistent with the result from comparison of anomaly time series from MSU and EQU in section $3 \mathrm{a}$.

\section{c. Seasonal difference of layer temperature trends over China}

The seasonal difference of upper-air temperature trends may have some relevance to detection and attribution of climate change in conjunction with the strong seasonality of ozone depletion in the stratosphere, as well as with the tropospheric response to increases in greenhouse gases and seasonal aerosol effect. Here, we investigate the monthly variation of trends of five layer temperatures from MSU and EQU during 1979-2018. As shown in Fig. 9, the seasonal difference of trend in TLS and TLT is more prominent than that in TMT, TTT, and TTS. For TLS, more cooling trends in late 

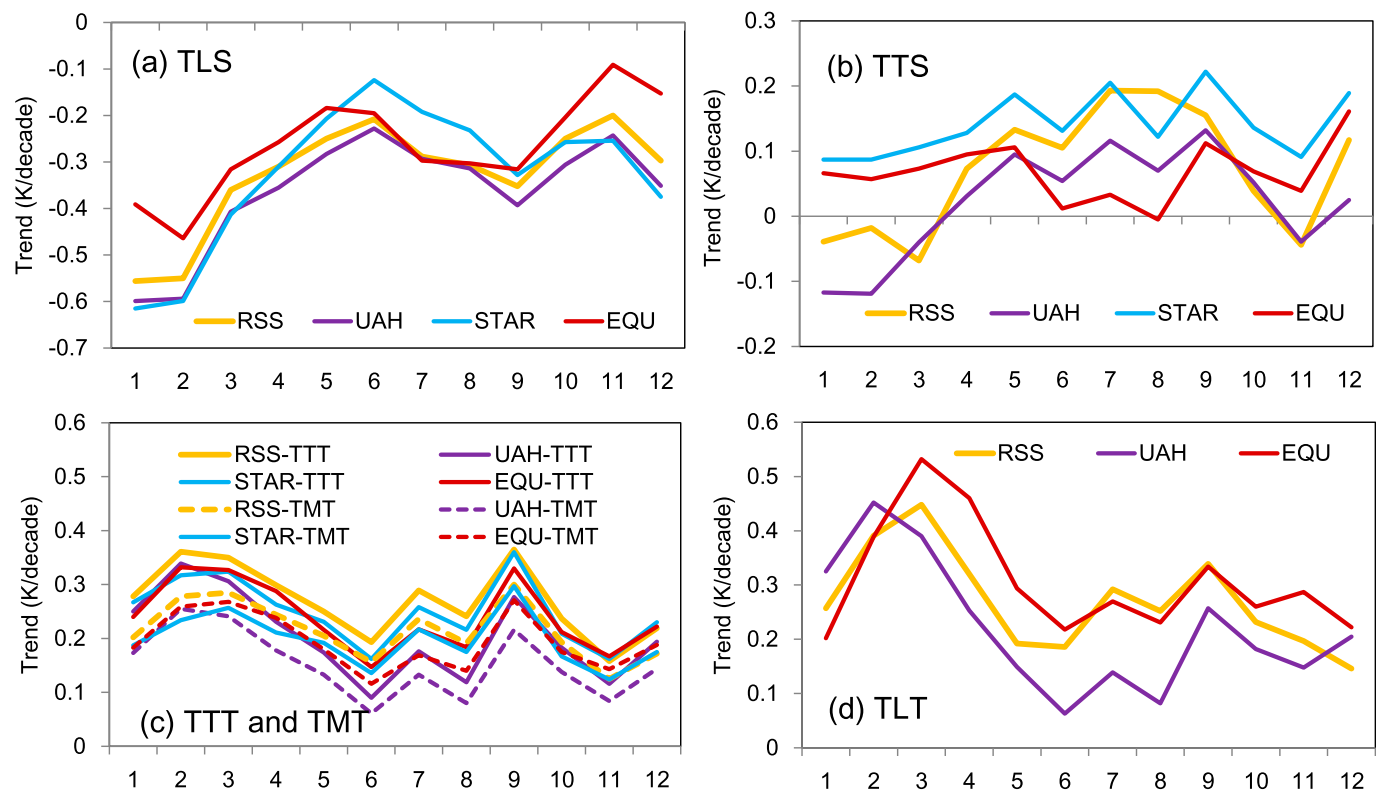

FIG. 9. Monthly variations of layer temperature trends during 1979-2018 from MSU (RSS, UAH, and STAR) and EQU: (a) TLS, (b) TTS, (c) TTT and TMT, and (d) TLT.

winter (February) to spring are coincident with the most significant ozone depletion over China (Duan 2007). The larger warming trends in TLT in March and February are due to the larger warming effects of absorbing aerosols in winter and spring in eastern China in addition to greenhouse warming effects. While the smaller warming trends in TLT in June and August are due to the larger effects of aerosols in summer in China (Jacobson 2001; Yu et al. 2001; Menon et al. 2002). The variation of trends in TMT and TTT is similar to that in TLT, and the consistency among MSU datasets and EQU is higher than for other layers. TTS trends from MSU exhibit more prominent seasonal difference than EQU with larger warming trends from May to September during summer months.

\section{d. Regional difference of layer temperature trends}

The trends of temperature in six subregions of China are shown in Fig. 10 and also reveal a significant regional difference. Trends are stronger in western or northern subregions (the Tibetan Plateau and southwestern, northwestern, and northern China; i.e., subregions 6, 5, 4, and 1) but those in the southern and eastern subregions are weaker. Take RSS for example: TLT warming trends are $0.40,0.37,0.33,0.26,0.20$, and $0.14 \mathrm{~K} \mathrm{decade}^{-1}$ in subregions $6,4,5,1,2$, and 3 , respectively. TLS shows stronger cooling trends in western subregions from MSU (subregions 4 and 5)

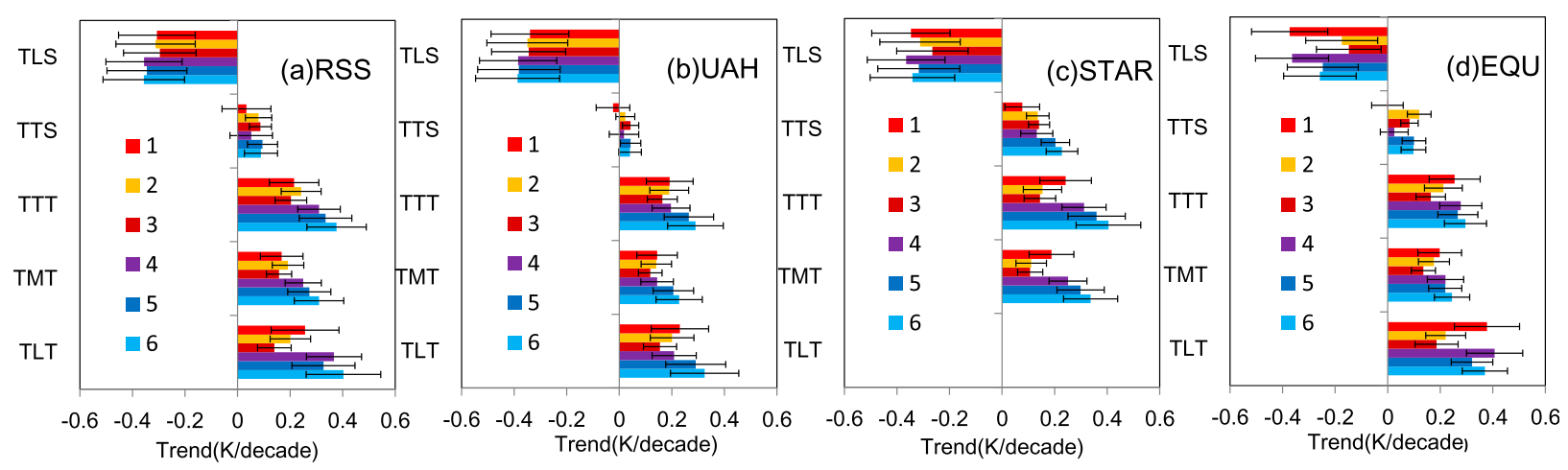

FIG. 10. Vertical structure of linear trends $\left(\mathrm{K} \mathrm{decade}^{-1}\right)$ of layer temperature anomalies averaged over six subregions in China during 1979-2018 from MSU (RSS, UAH, and STAR) and EQU. The superimposed lines on trend are uncertainties at 95\% significance level. (a) RSS, (b) UAH, (c) STAR, and (d) EQU. 



FIG. 11. Spatial distribution of layer temperature trend over China during 1979-2018 from EQU and MSU (RSS, UAH, and STAR). From top to bottom are TLS, TTS, TTT, TMT, and TLT.

and in northern subregions from EQU (subregions 1 and 4). The warming trends over six subregions from STAR are stronger, especially in TTS. TTT, TMT, and TLT from both MSU and EQU show significant warming trends and are stronger in western China (subregions 5 and 4), especially in the Tibetan Plateau (subregion 6). The larger discrepancies in TTS trends between EQU and MSU in the subregions are generally consistent with the discrepancies in TTS over the whole of China. This is reasonable since the TTS trend represents the combination of warming in the upper troposphere and cooling in the lower stratosphere. The other reason is that the residual discontinuities of temperatures in the upper troposphere and lower stratosphere from radiosonde observation are larger (Guo et al. 2019); this is further analyzed at individual stations in section $3 \mathrm{e}$.
Figure 11 exhibits a spatial distribution of layer temperature trends at stations over China during 1979-2018 from MSU (RSS, UAH, and STAR) and EQU. The patterns of trends in TLS, TTT, TMT, and TLT are similar from MSU and EQU. The significant TLS cooling trends at most stations in China from all MSU datasets while TLS trends from EQU show more regional difference and the cooling trends in northern China are stronger than those in southern China. TTS trends are weaker because the layer is around tropopause and the warming trends in upper troposphere and cooling trends in lower stratosphere counteract each other. The magnitudes of TTS from RSS and STAR are larger at most stations in China, while those from EQU and UAH are smaller and can be negative in parts of northern China. 


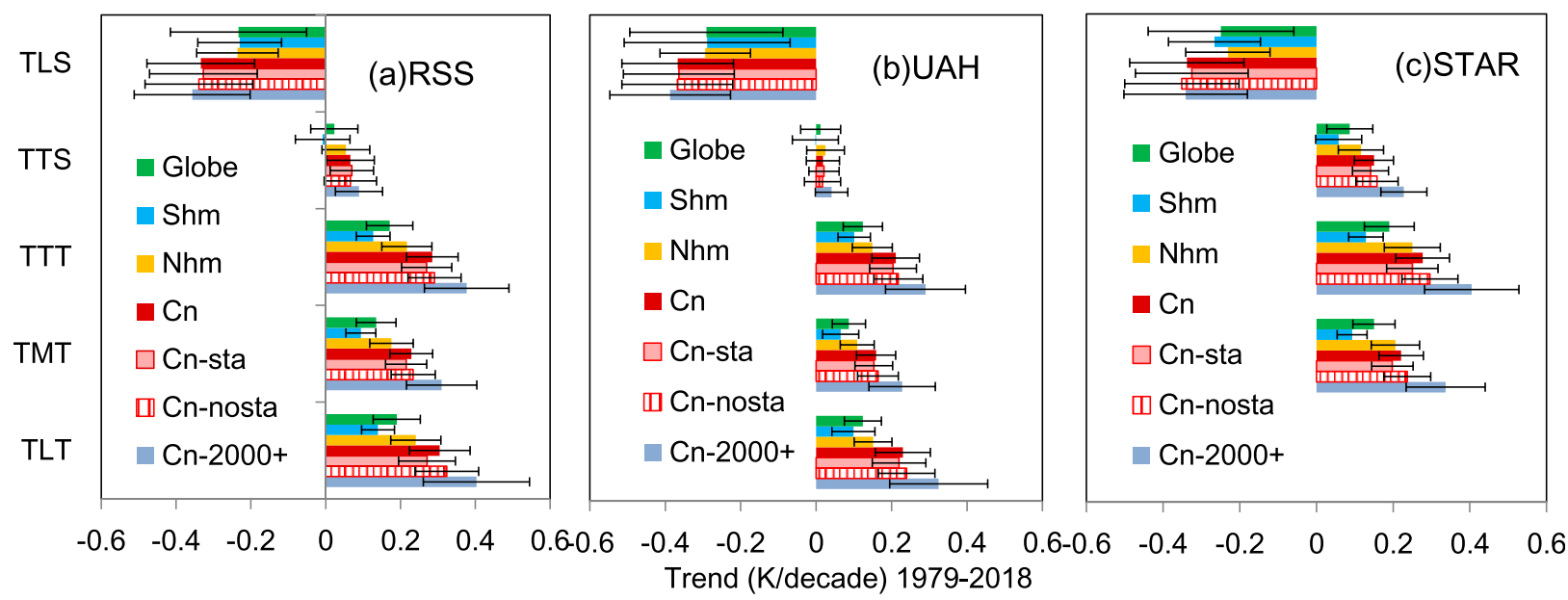

FIG. 12. Linear trends (K decade ${ }^{-1}$ ) of monthly layer temperature anomalies during 1979-2018 averaged over the globe and the Northern and Southern Hemispheres (Globe, Nhm, and Shm) and China (Cn, Cn-sta, Cn-nosta, and Cn-2000+) from RSS, UAH, and STAR. Superimposed lines on the trend bars are uncertainties at the $95 \%$ significance level.

TLT, TMT, and TTT from MSU datasets and EQU show warming trends at most stations in China, stronger particularly in western and northern China, which are consistent with the results from regional mean time series.

Figure 12 addresses the regional feature of the temperature trends from MSU at a larger scale through the linear trends of the monthly layer mean temperature anomalies averaged over the globe, the Northern and Southern Hemispheres separately, and China with four samplings from RSS, UAH, and STAR during 1979-2018. The warming trends in troposphere and cooling trends in TLS over China are stronger than those at global and hemispheric scales. The difference of trends indicates the necessity of study on a regional scale. For China region, warming trends of TLT, TMT,TTT, and TTS by Cn-2000+ and $\mathrm{Cn}$-nosta are stronger than those by $\mathrm{Cn}$ and $\mathrm{Cn}$-sta. Trends from $2000+$ exhibit the strongest warming in troposphere and cooling in TLS; the trends of nosta and Cn follow and that of sta is the weakest. This is consistent with the stronger warming trends over western and northern China where there are fewer stations, especially in the Tibetan Plateau. This regional difference of trend indicates that satellite MSU temperature is superior to the estimates from in situ observations for the regions with fewer stations such as the Tibetan Plateau. On the other hand, the larger discrepancy between MSU and EQU over the Tibetan Plateau suggests a larger uncertainty and needs additional independent data in higher spatial and temporal resolution in our further studies.

\section{e. Comparisons of temperature anomaly at individual stations over China}

The difference between MSU and EQU and discontinuity caused by system change can be well illustrated by a comparison of temperature anomalies at individual stations because the metadata at a station can provide the exact information on the instrument replacement or location changes and help to diagnose the artificial influence caused by observing system changes.

Figures 13 and 14 exhibit the distribution of correlation and RMSD of layer temperatures from MSU (RSS, $\mathrm{UAH}$, and STAR) and radiosonde (EQU) at 113 stations in China during 1979-2018. TLS, TTT, and TMT over most of China and TTS over northern China show excellent agreements with statistically significant positive correlation $(>0.9)$ and smaller RMSD $(<0.5)$. The lower correlation in TLS than that in TMT in southeastern China is likely related to more missing data from radiosonde temperature at higher levels $(200,100,50$, and $30 \mathrm{hPa}$ ) in southern China replaced by climatology and larger uncertainty in TLS from homogenization (Guo et al. 2019). More discrepancy is found in TLT, which is consistent with the results from regional and subregional mean anomalies and trend (Table 2, Figs. 3 , 4 , and 8 ). This result is reasonable since the construction process of TLT introduces additional noise and diurnal adjustment may increase the uncertainty (Mears et al. 2011). In addition, a larger discrepancy between MSU and EQU appears in the Tibetan Plateau and southern China with a lower correlation and larger RMSD. Lower correlations in TLT are in southern China and those in TMT are the Tibetan Plateau. Larger RMSD in TLT between RSS (or UAH) and EQU is found in most of China and three larger value centers are in the regions with variable topography. The smaller RMSD of TLT UAH in the Tibetan Plateau indicates better agreement with TLT EQU, which is related to the increase of TLT weighting function peak height in UAH 6.0 (Spencer 



FIG. 13. Spatial distribution of correlation from monthly temperature anomalies between MSU (RSS, UAH, and STAR) and EQU over China during 1979-2018. From top to bottom are TLS, TTS, TTT, TMT, and TLT; from left to right are RSS, UAH, and STAR. 

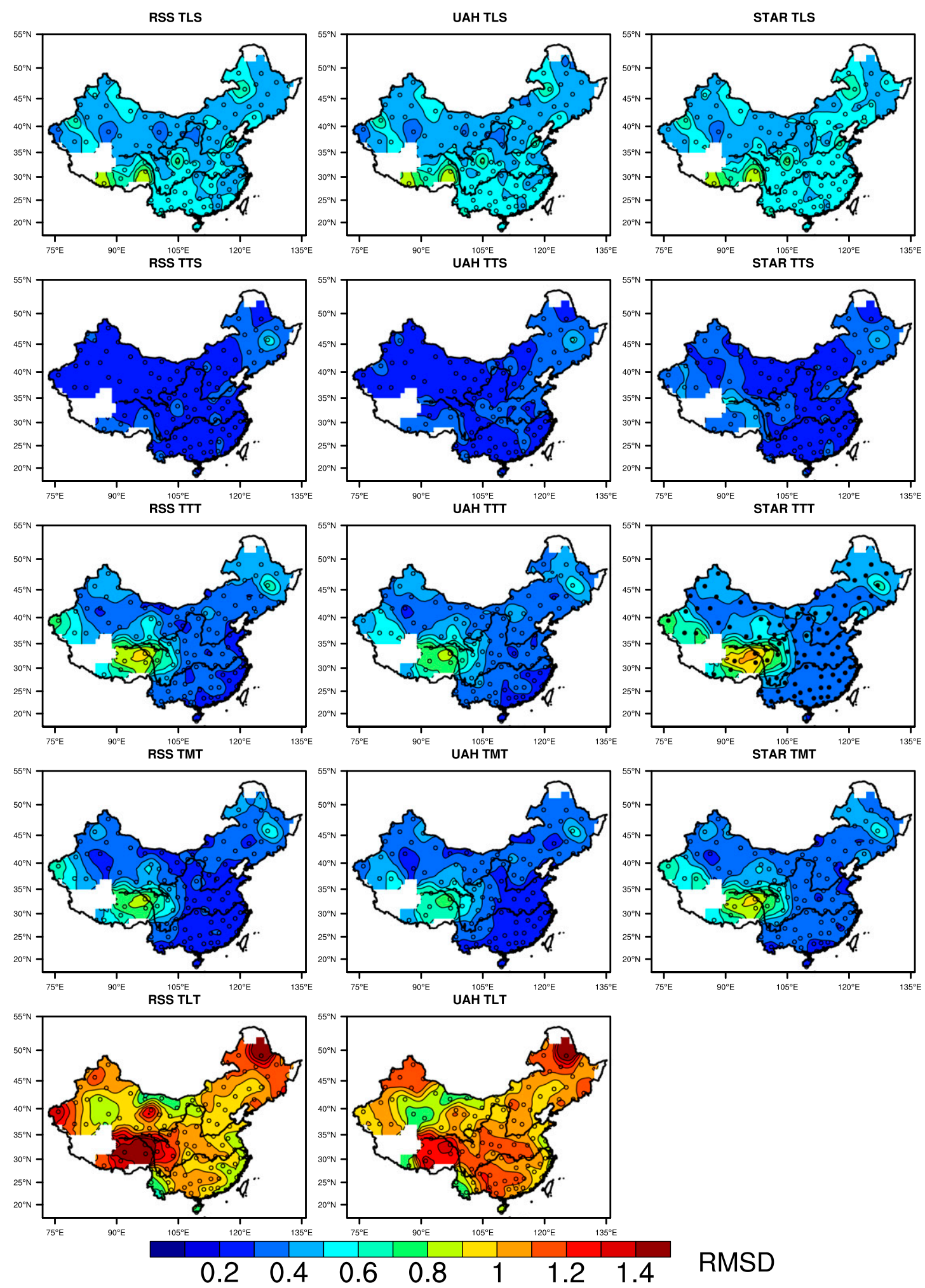

FIG. 14. Spatial distribution of RMSD from monthly temperature anomaly over China during 1979-2018 between MSU (RSS, UAH, and STAR) and EQU. From top to bottom are TLS, TTS, TTT, TMT, and TLT; from left to right are RSS, UAH, and STAR. 



FIG. 15. Monthly anomaly difference (K) with EQU from RSS, UAH, and STAR during 1979-2018 and the average during periods according to the radiosonde system or instrument replacement. UAH and STAR are offset vertically for better viewing, and the black triangles represent the timing of radiosonde changes. Shown are (a) TLS at 56029, (b) TTS at 59293, (c) TMT at 59431, and (d) TLT at 56137.

et al. 2017). A larger discrepancy in southern China and the Tibetan Plateau between MSU and EQU might be related to the impacts of hydrometeors on MSU trends, which were studied in the past and remain a debatable issue (Prabhakara et al. 1995, 1996; Spencer et al. 1990, 1996). Weng et al. (2014) pointed out that the emission and scattering of clouds and precipitation modulate MSU and AMSU-A brightness temperatures for a given atmospheric temperature condition. The global mean trends TLT and TMT for 1998-2010 become 20\%-30\% higher when cloud-affected brightness temperature measurements are removed from the AMSU data. Pahlavan et al. (2018) showed the robust linear relationship between temperature deficit and precipitation and confirmed that the cooling effect of hydrometeors could change local trends by as much as $15 \%$ for TMT and $30 \%$ for TLT over the tropical oceans. Therefore, considering the distribution of precipitation and clouds (Ren et al. 2015; Liu et al. 2004) and topography in China, the larger discrepancy of TLT and TMT in southern China and the Tibetan Plateau may be related to many factors such as the effects of clouds and precipitation, complex topography, and surface emission, which lead to a larger uncertainty in converting the in situ temperatures to EQU.

Four stations with larger discrepancies (the larger red squares in Fig. 1) are selected to analyze monthly difference with EQU from MSU datasets during 19792018 and the average during different periods according to radiosonde system and instrument changes (Fig. 15). The major radiosonde changes include system upgrades in 1999-2001 over China and instrument changes from 2002 to 2010 at individual stations. For example, instruments changed in January 2009 at station 56029, in April 2007 at 59293, in November 2006 and January 2009 at 59431, and in May 2010 at 56137. The averaged differences during different periods at four stations present stepwise changes, indicating the residual discontinuities in EQU if no systematic change for satellite MSU in same period. The difference time series from all MSU datasets generally show a high consistency with the similar phase and magnitude in variability especially in TLS and TTS. This suggests that TLS and TTS from different MSU either all represent the reality very well or have common issues if their merging is imperfect, especially during the period for radiosonde system upgrading or instrument change in 2000s (Guo et al. 2019). The differences of trends in TLS, TTS, and TLT between MSU and EQU are larger than those from MSU datasets (Table 3). The obvious differences of trend in TLS at 56029 and TTS at 59293 are mainly related to the discontinuities caused by radiosonde system changes in the 2000s and more missing data (replaced by climatology) in southern China and the Tibetan Plateau (Guo 
TABLE 3. Linear trends ( $\mathrm{K}$ decade ${ }^{-1}$ ) of layer mean temperatures during 1979-2018 at four representative stations from MSU (UAH, RSS, and STAR) and radiosonde equivalent (EQU) (bold means significance at the $95 \%$ level).

\begin{tabular}{lccrc}
\hline \hline Layer & TLT & TMT & TTS & TLS \\
\hline Station & 56137 & 59431 & 59293 & 56029 \\
RSS & $\mathbf{0 . 4 4}$ & $\mathbf{0 . 1 7}$ & 0.09 & $\mathbf{- 0 . 3 6}$ \\
UAH & $\mathbf{0 . 4 3}$ & $\mathbf{0 . 1 3}$ & 0.04 & $\mathbf{- 0 . 3 9}$ \\
STAR & - & 0.08 & $\mathbf{0 . 1 5}$ & $\mathbf{- 0 . 3 7}$ \\
EQU & 0.12 & $\mathbf{0 . 1 7}$ & $\mathbf{- 0 . 1 5}$ & $\mathbf{- 0 . 3 1}$ \\
\hline
\end{tabular}

et al. 2019). The TMT trend difference at 59431 among MSU datasets is larger than that between MSU and EQU with weaker warming trend from STAR than those from RSS, UAH, and EQU (Table 3). TMT difference with EQU from STAR at 59431 are reduced more significantly than other MSU datasets after 2007, which are related to the merging difference for $N O A A$ 15 and $N O A A-14$. This result indicates the uncertainties in TMT trends at 59431 are mainly related to the discontinuities caused by satellite system change. TLT difference with EQU from RSS and UAH at 56137 show a larger fluctuation range than that in other layers. A larger TLT inconsistency between satellite MSU and EQU is related to the TLT construction and diurnal adjustment from MSU data and sparse sampling and varied topography effect for in situ observation (Pepin and Seidel 2005). In addition, TLT difference with EQU at 56137 from RSS and UAH increased obviously from second the half of 2014. Since there is no metadata event record after 2011 at 56137, the stepwise change of difference with EQU during 2011-18 is related to satellite system changes and the residual intersatellite biases, which contribute to the trend difference between EQU and MSU. The effect of precipitation and complex topography may be also one of the factors that result in a larger discrepancy in TMT at 59431 and TLT at 56137 trends from MSU and EQU. Therefore, the methodologies for constructing both homogenized MSU and radiosonde equivalent datasets may contain biases that lead to the trend differences (Thorne et al. 2005a, 2011; Mears et al. 2011, 2012; Mears and Wentz 2016, 2017; Spencer et al. 2017). The residual discontinuities remained in the historical time series of upper-air temperature from satellite MSU or homogenized radiosonde datasets may still affect the long-term trend analysis. It is highly desired that the benchmark be established as a reference that could constrain the temperature trends observed by different types of instruments (Guo and Ding 2011; Guo et al. 2019). The mutual validation at individual grids (or stations) with the accurate metadata records are valuable to identify the bias caused by the system change and help to improve the reliability of upper-air temperatures from satellite and radiosonde observations.

Considering the uncertainty in homogenization and merging time series from radiosonde and satellite temperature and equivalent conversion, it is necessary to do more experiments in radiative transfer simulations and compare the simulated MSU equivalents with three known MSU datasets from UAH, RSS, and STAR. Those quality-controlled radiosonde observation data from Integrated Global Radiosonde Archive (IGRA) (Durre et al. 2006) and homogenized radiosonde observation data from HadAT, RATPAC, RAOBCORE, RICH, and IUK could be very valuable sources for our future studies.

\section{Summary and conclusions}

To extract region climate signal from satellite microwave observations (MSU) over China, we examined layer mean temperatures in TLT, TMT, TTT, TTS, and TLS during 1979-2018 from RSS, UAH, and STAR and compared with the proxy MSU dataset simulated from homogenized surface and radiosonde temperatures (EQU) by RTTOV at 113 stations in China. These analyses are the first conducted at the China regional scale and provide an overall evaluation of long-term trend and uncertainty of upper-air temperatures over past 40 years. Specifically, the long-term variability, seasonal, and regional difference of trends are also compared. The radiosonde metadata records at stations and the information on satellites merging improve our insight into the cause of the difference between MSU and EQU. The most important findings are summarized as follows.

The layer mean temperatures anomalies over China from MSU and EQU show a good agreement and have a high correlation between MSU and EQU with similar standard deviations and small root-mean-square deviations in China during 1979-2018. Major differences between MSU and EQU are related to the changes in both satellite instruments and radiosonde systems. The differences during 1979-98 are mainly related to the discontinuities caused by satellite system changes, while those during 1999-2018 are mainly related to radiosonde system changes in the 2000s over China. This finding is revealed by the comparison of anomaly time series and trend at regional mean scale or individual stations from MSU and EQU and confirmed by the information on the system changes including satellite merging and metadata records in China.

Trends of China-mean temperatures from MSU and EQU show a common feature with warming in troposphere and cooling in lower stratosphere during 19792018. The magnitude ranges are $0.22-0.31 \mathrm{~K} \mathrm{decade}^{-1}$ in 
TLT, $0.15-0.22 \mathrm{~K}$ decade $^{-1}$ in TMT, $0.20-0.27 \mathrm{~K}$ decade $^{-1}$ in TTT, $0.02-0.14 \mathrm{~K}$ decade $^{-1}$ in TTS, and from -0.26 to $-0.36 \mathrm{~K} \mathrm{decade}^{-1}$ in TLS. RSS generally shows better agreements with EQU. UAH shows a less warming in TLT and TMT and more cooling trends in TLS whereas STAR is opposite. The warming trends in troposphere and cooling trends in lower stratosphere from all datasets are stronger in 1979-98 and obviously weaken during 19992018. The $1997 / 98$ strong ENSO and the major volcanic eruptions in 1991 and 1982 significantly contribute to the trends during 1979-98. The seasonal difference in trend is prominent in TLT and TLS, with stronger warming TLT trends in March, February, and September and strong cooling trends in TLS from late winter to spring. Regional features of trends show strong warming trends in western or northern China, especially over the Tibetan Plateau.

A larger discrepancy between MSU and EQU is found in TLT, which is reasonable because its construction process introduces more additional noise than other layers. More significant differences between MSU and EQU appear in the Tibetan Plateau and southern China with lower correlation and larger RMSD, for the residual discontinuities caused by system changes. In addition, more complex topography in the Tibetan Plateau and more precipitation in southern China lead to larger uncertainty in conversion from in situ temperatures to MSU equivalents.

The impact of different sampling on regional mean temperature over China is not as significant as those on hemispheric or global scales since China has a denser radiosonde network. MSU temperatures over the Tibetan Plateau vary with larger amplitudes than other regions in China. Trend comparisons show certain differences by four samplings in China, especially in TLT and TMT. The regions with higher elevation stations $(>2000 \mathrm{~m})$ show the strongest warming trends in the troposphere (TLT, TMT, TTT, TTS) and a cooling trend in TLS, the regions without stations (nosta) and the whole of China ( $\mathrm{Cn}$ ) follow, and the regions with stations (sta) show the weakest trends. This difference suggests that satellite MSU temperature is superior to in situ observation in trend estimate over such regions with fewer stations, especially over the Tibetan Plateau. On the other hand, the larger discrepancy between MSU and EQU over the Tibetan Plateau and the amplitude of anomalies from three MSU datasets are obviously larger than EQU. This difference may be indicative of problems associated with the conversion from in situ observation to MSU equivalents or three MSU datasets may have some common issues in higher altitude regions. Further study is needed including additional independent data with higher spatial and temporal resolutions.

In summary, we first assessed the consistency of upper-air temperature between MSU and EQU and quantitatively evaluated the long-term trend and uncertainty of upper-air temperature in China during the past 40 years. The conclusions on consistency between EQU and MSU may be used as a background for future application of upper-air temperature over China. The evidence of the discrepancy between MSU and EQU provide useful information on the possible residual discontinuity in the historical temperatures from both satellite MSU and in situ observations. Further adjustment at individual grid or stations will be conducted over China through this cross-validation and may improve homogenization or merging approach. Therefore, the comparison and validation between MSU and in situ data are necessary for long-term trend and uncertainty estimates. More information of system change with exact timing or locations is valuable to identify the bias caused by artificial changes and can help to improve the reliability of upper-air temperatures.

Acknowledgments. The authors thank three reviewers for their helpful suggestions. This work is supported by the National Key Research and Development Program of China (Grants 2018YFC1509002, 2018YFC1506501, and 2016YFA0600301-05), the National Natural Science Fund of China (41675094 and 41775082) and Climate Change Special Fund of China Meteorological Administration (CCSF201917). We thank Remote Sensing System (RSS), University of Alabama Huntsville (UAH), NOAA's Satellite Applications and Research (STAR), and Chinese National Meteorological Information Centre (NMIC)/China Meteorological Administration (CMA) for providing MSU and radiosonde temperature data.

\section{REFERENCES}

Cao, L. J., Y. N. Zhu, G. L. Tang, F. Yuan, and Z. W. Yan, 2016: Climate warming in China according to a homogenized data set from 2419 stations. Int. J. Climatol., 36, 4384-4392, https:// doi.org/10.1002/joc.4639.

Chen, Z., and S. Yang, 2014: Homogenization and analysis of China radiosonde temperature data from 1979 to 2012 (in Chinese). Acta Meteor. Sin., 72, 794-804, https://doi.org/ 10.11676/QXXb2014.046.

Chipperfield, M. P., and Coauthors, 2017: Detecting recovery of the stratospheric ozone layer. Nature, 549, 211-218, https:// doi.org/10.1038/nature23681.

Christy, J. R., and W. B. Norris, 2006: Satellite and VIZ-radiosonde intercomparisons for diagnosis of nonclimatic influences. J. Atmos. Oceanic Technol., 23, 1181-1194, https://doi.org/ 10.1175/JTECH1937.1.

$\longrightarrow$, and - 2009: Discontinuity issues with radiosonde and satellite temperatures in the Australian region 1979-2006. J. Atmos. Oceanic Technol., 26, 508-522, https://doi.org/ 10.1175/2008JTECHA1126.1.

, R. W. Spencer, W. B. Norris, W. D. Braswell, and D. E. Parker, 2003: Error estimates of version 5.0 of MSU-AMSU 
bulk atmospheric temperatures. J. Atmos. Oceanic Technol., 20, 613-629, https://doi.org/10.1175/1520-0426(2003)20<613: EEOVOM $>2.0 . \mathrm{CO} ; 2$.

—, W. B. Norris, R. W. Spencer, and J. J. Hnilo, 2007: Tropospheric temperature change since 1979 from tropical radiosonde and satellite measurements. J. Geophys. Res., 112, D06102, https://doi.org/10.1029/2005JD006881.

— - R. W. Spencer, W. D. Braswell, and R. Junod, 2018: Examination of space-based bulk atmospheric temperatures used in climate research. Int. J. Remote Sens., 39, 3580-3607, https://doi.org/10.1080/01431161.2018.1444293.

Duan, A., 2007: Cooling trend in the upper troposphere and lower stratosphere over China. Geophys. Res. Lett., 34, L15708, https://doi.org/10.1029/2007GL029667.

Durre, I., R. S. Vose, and D. B. Wuertz, 2006: Overview of the Integrated Global Radiosonde Archive. J. Climate, 19, 53-68, https://doi.org/10.1175/JCLI3594.1.

Free, M., D. J. Seidel, J. K. Angell, J. Lanzante, I. Durre, and T. C. Peterson, 2005: Radiosonde Atmospheric Temperature Products for Assessing Climate (RATPAC): A new data set of large-area anomaly time series. J. Geophys. Res., 110, D22101, https:// doi.org/10.1029/2005JD006169.

Fu, Q., and C. M. Johanson, 2005: Satellite-derived vertical dependence of tropical tropospheric temperature trends. Geophys. Res. Lett., 32, L10703, https://doi.org/10.1029/2004GL022266.

Guo, Y. J., and Y. H. Ding, 2009: Long-term free-atmosphere temperature trends in China derived from homogenized in situ radiosonde temperature series. J. Climate, 22, 1037-1051, https://doi.org/10.1175/2008JCLI2480.1.

$\longrightarrow$, and — 2011: Impacts of reference time series on the homogenization of radiosonde temperature. Adv. Atmos. Sci., 28, 1011-1022, https://doi.org/10.1007/s00376-010-9211-3.

_ certainties over China in recent 60 years (in Chinese). Acta Meteor. Sin., 77, 1073-1085, https://doi.org/10.11676/qxxb2019.061.

— , P. W. Thorne, M. P. McCarthy, H. A. Titchner, B. X. Huang, P. M. Zhai, and Y. H. Ding, 2008: Radiosonde temperature trends and their uncertainties over eastern China. Int. J. Climatol., 28, 1269-1281, https://doi.org/10.1002/joc.1633.

—, S. Q. Zhang, J. H. Yan, X. Ruan, and Z. Chen, 2016: A comparison of atmospheric temperature over China between radiosonde observation and multiple reanalysis datasets. J. Meteor. Res., 30, 242-257, https://doi.org/10.1007/s13351016-5169-0.

— C. Zou, P. Zhai, and G. Wang, 2019: An analysis of the discontinuity in Chinese radiosonde temperature data using satellite observation as a reference. J. Meteor. Res., 33, 289-306, https://doi.org/10.1007/s13351-019-8130-1.

Haimberger, L., 2007: Homogenization of radiosonde temperature time series using innovation statistics. J. Climate, 20, 13771403, https://doi.org/10.1175/JCLI4050.1.

- C. Tavolato, and S. Sperka, 2008: Toward elimination of the warm bias in historic radiosonde temperature records-Some new results from a comprehensive intercomparison of upperair data. J. Climate, 21, 4587-4606, https://doi.org/10.1175/ 2008JCLI1929.1.

,-- , and,- 2012 : Homogenization of the global radiosonde dataset through combined comparison with reanalysis background series and neighboring stations. J. Climate, 25, 8108-8131, https://doi.org/10.1175/JCLI-D-11-00668.1.

$\mathrm{Hu}, \mathrm{Y}$., and K.-K. Tung, 2003: Possible ozone induced long-term changes in planetary wave activity in later winter. J. Climate, 16, 3027-3038, https:// doi.org/10.1175/1520-0442(2003)016<3027:POLCIP>2.0.CO;2.
Hurrell, J. W., S. J. Brown, K. E. Trenberth, and J. R. Christy, 2000: Comparison of tropospheric temperatures from radiosondes and satellites: 1979-98. Bull. Amer. Meteor. Soc., 81, 2165-2178, https:// doi.org/10.1175/1520-0477(2000)081<2165:COTTFR>2.3.CO;2.

IPCC, 2013: Climate Change 2013: The Physical Science Basis. T. F. Stocker et al., Eds., Cambridge University Press, 1535 pp., https://doi.org/10.1017/CBO9781107415324.

Jacobson, M. Z., 2001: Strong radiative heating due to the mixing state of black carbon in atmospheric aerosols. Nature, 409, 695-697, https://doi.org/10.1038/35055518.

Liao, M., P. Zhang, X. Wu, and H. Qiu, 2011: Research advances of the temperature changes in the upper air using MSU time series (in Chinese). Meteor. Mon., 37, 1151-1157.

Liu, R., Y. Liu, and B. Du, 2004: Cloud climatology characteristics of China from ISCCP data (in Chinese). J. Appl. Meteor. Sci., 15, 468-476.

Mears, C. A., and F. J. Wentz, 2009a: Construction of the remote sensing systems V3.2 atmospheric temperature records from the MSU and AMSU microwave sounders. J. Atmos. Oceanic Technol., 26, 10401056, https://doi.org/10.1175/2008JTECHA1176.1.

— , and $-2009 \mathrm{~b}$ : Construction of the RSS V3.2 lowertropospheric temperature dataset from the MSU and AMSU microwave sounders. J. Atmos. Oceanic Technol., 26, 1493 1509, https://doi.org/10.1175/2009JTECHA1237.1.

$\longrightarrow$, and — 2016: Sensitivity of satellite-derived tropospheric temperature trends to the diurnal cycle adjustment. J. Climate, 29, 3629-3646, https://doi.org/10.1175/JCLI-D-15-0744.1.

_- and - 2017: A satellite-derived lower tropospheric atmospheric temperature dataset using an optimized adjustment for diurnal effects. J. Climate, 30, 7695-7718, https://doi.org/ 10.1175/JCLI-D-16-0768.1.

_, M. C. Schabel, and F. J. Wentz, 2003: A reanalysis of the MSU channel 2 tropospheric temperature record. J. Climate, 16, 3650-3664, https:// doi.org/10.1175/1520-0442(2003)016<3650:AROTMC > 2.0.CO;2.

— F. J. Wentz, P. Thorne, and D. Bernie, 2011: Assessing uncertainty in estimates of atmospheric temperature changes from MSU and AMSU using a Monte-Carlo estimation technique. J. Geophys. Res., 116, D08112, https://doi.org/ 10.1029/2010JD014954.

- - , and P. W. Thorne, 2012: Assessing the value of Microwave Sounding Unit-radiosonde comparisons in ascertaining errors in climate data records of tropospheric temperatures. J. Geophys. Res., 117, D19103, https://doi.org/ 10.1029/2012JD017710.

Menon, S., J. Hansen, L. Nazarenko, and Y. Luo, 2002: Climate effects of black carbon aerosols in China and India. Science, 297, 2250-2253, https://doi.org/10.1126/science.1075159.

Pahlavan, H., Q. Fu, and J. M. Wallace, 2018: The effect of hydrometeors on MSU/AMSU temperature observations over the tropical ocean. J. Atmos. Oceanic Technol., 35, 1141-1150, https://doi.org/10.1175/JTECH-D-17-0190.1.

Pepin, N. C., and D. J. Seidel, 2005: A global comparison of surface and free-air temperatures at high elevations. J. Geophys. Res., 110, D03104, https://doi.org/10.1029/2004JD005047.

Po-Chedley, S., and Q. Fu, 2012: A bias in the midtropospheric channel warm target factor on the NOAA-9 Microwave Sounding Unit. J. Atmos. Oceanic Technol., 29, 646-652, https://doi.org/10.1175/JTECH-D-11-00147.1.

_ , T. J. Thorsen, and Q. Fu, 2015: Removing diurnal cycle contamination in satellite-derived tropospheric temperatures: Understanding tropical tropospheric trend discrepancies. J. Climate, 28, 2274-2290, https://doi.org/10.1175/JCLI-D-1300767.1. 
Prabhakara, C., J. Nucciarone, and J.-M. Yoo, 1995: Examination of global atmospheric temperature monitoring with satellite microwave measurements: 1 . Theoretical considerations. Climatic Change, 30, 349-366, https://doi.org/10.1007/BF01091931.

_, J.-M. Yoo, S. P. Maloney, J. Nucciarone, A. Arking, M. Cadeddu, and G. Dalu, 1996: Examination of global atmospheric temperature monitoring with satellite microwave measurements: 2. Analysis of satellite data. Climatic Change, 33, 459-476, https://doi.org/10.1007/BF00141699.

Randall, R. M., and B. M. Herman, 2008: Using limited time period trends as a means to determine attribution of discrepancies in Microwave Sounding Unit-derived tropospheric temperature time series. J. Geophys. Res., 113, D05105, https://doi.org/ 10.1029/2007JD008864.

Randel, W. J., and F. Wu, 1999: Cooling of the Arctic and Antarctic polar stratospheres due to ozone depletion. J. Climate, 12, 1467-1479, https://doi.org/10.1175/1520-0442(1999)012<1467: COTAAA $>2.0 . \mathrm{CO} ; 2$.

$\longrightarrow$, and — 2006: Biases in stratospheric and tropospheric temperature trends derived from historical radiosonde data. J. Climate, 19, 2094-2104, https://doi.org/10.1175/JCLI3717.1.

Ren, G., Y. Zhan, Y. Ren, Y. Chen, T. Wang, Y. Liu, and X. Sun, 2015 Spatial and temporal patterns of precipitation variability over mainland China: I. Climatology (in Chinese). Adv. Water Sci., 26, 299-310, https://doi.org/10.14042/J.CNKI.32.1309.2015.03.001.

Saunders, R., and Coauthors, 2018: An update on the RTTOV fast radiative transfer model (currently at version 12). Geosci. Model Dev., 11, 2717-2737, https://doi.org/10.5194/gmd-112717-2018.

Seidel, D. J., and Coauthors, 2004: Uncertainty in signals of largescale climate variations in radiosonde and satellite upper-air temperature datasets. J. Climate, 17, 2225-2240, https://doi.org/ 10.1175/1520-0442(2004)017<2225:UISOLC > 2.0.CO;2.

_ , and Coauthors, 2009: Reference upper-air observations for climate: Rationale, progress, and plans. Bull. Amer. Meteor. Soc., 90, 361-369, https://doi.org/10.1175/2008BAMS2540.1.

_, N. P. Gillett, J. R. Lanzante, K. P. Shine, and P. W. Thorne, 2011: Stratospheric temperature trends: Our evolving understanding. Wiley Interdiscip. Rev.: Climate Change, 2, 592-616, https://doi.org/10.1002/WCC.125.

Sherwood, S. C., and N. Nishant, 2015: Atmospheric changes through 2012 as shown by iteratively homogenised radiosonde temperature and wind data (IUKv2). Environ. Res. Lett., 10, 054007, https://doi.org/10.1088/1748-9326/10/5/054007.

Spencer, R. W., and J. R. Christy, 1992: Precision and radiosonde validation of satellite gridpoint temperature anomalies. Part II A tropospheric retrieval and trends during 1979-1990. J. Climate, 5, 858-866, https://doi.org/10.1175/1520-0442(1992) $005<0858:$ PARVOS $>2.0$.CO; 2 .

,-- , and N. C. Grody, 1990: Global atmospheric temperature monitoring with satellite microwave measurements: Method and results 1979-84. J. Climate, 3, 1111-1128, https://doi.org/ 10.1175/1520-0442(1990)003<1111:GATMWS > 2.0.CO;2.

_ _ - and _ 1996: A technical comment: Analysis of 'Examination of "Global atmospheric temperature monitoring with satellite microwave measurements." Climatic Change, $\mathbf{3 3}$, 477-489, https://doi.org/10.1007/BF00141700.
,-- , and D. B. Braswell, 2017: UAH version 6 global satellite temperature products: Methodology and results. Asia Pac. J. Atmos. Sci., 53, 121-130, https://doi.org/10.1007/S13143-0170010-Y.

Thorne, P. W., D. E. Parker, J. R. Christy, and C. A. Mears, 2005a: Uncertainties in climate trends: Lessons from upper-air temperature records. Bull. Amer. Meteor. Soc., 86, 1437-1442, https://doi.org/10.1175/BAMS-86-10-1437.

,,-- S. F. B. Tett, P. D. Jones, M. McCarthy, H. Coleman, and P. Brohan, 2005b: Revisiting radiosonde upper air temperatures from 1958 to 2002. J. Geophys. Res., 110, D18105, https://doi.org/10.1029/2004JD005753.

_ J. R. Lanzante, T. C. Peterson, D. J. Seidel, and K. P. Shine, 2011: Tropospheric temperature trends: History of an ongoing controversy. Climatic Change, 2, 66-88, https://doi.org/ 10.1002/WCC. 80

Weng, F., X. Zou, and Z. Qin, 2014: Uncertainty of AMSU-A derived temperature trends in relationship with clouds and precipitation over ocean. Climate Dyn., 43, 1439-1448, https:// doi.org/10.1007/s00382-013-1958-7.

Xu, W. H., C. H. Sun, J. Q. Zuo, Z. G. Ma, W. J. Li, and S. Yang, 2019: Homogenization of monthly ground surface temperature in China during 1961-2016 and performances of GLDAS reanalysis products. J. Climate, 32, 1121-1135, https://doi.org/ 10.1175/JCLI-D-18-0275.1.

Yu, S., V. K. Saxena, and Z. Zhao, 2001: A comparison of signals of regional aerosol induced forcing in eastern China and the southeastern United States. Geophys. Res. Lett., 28, 713-716, https://doi.org/10.1029/2000GL011834.

Zhai, P. M., 1997: Some gross errors and biases in China's historical radiosonde data (in Chinese). Acta Meteor. Sin., 55, 563-572.

_, and R. E. Eskridge, 1996: Analyses of inhomogeneities in radiosonde temperature and humidity time series. J. Climate, 9, 884-894, https://doi.org/10.1175/1520-0442(1996)009<0884: AOIIRT $>2.0 . \mathrm{CO} ; 2$.

Zhang, S. Q., Y. J. Guo, and G. F. Wang, 2018: A comparative study of atmospheric humidity over China between radiosonde and the third generation reanalysis datasets (in Chinese). Acta Meteor. Sin., 76, 289-303, https://doi.org/ 10.11676/qxxb2017.095.

Zou, C.-Z., and W. Wang, 2011: Intersatellite calibration of AMSU-A observations for weather and climate applications. J. Geophys. Res., 116, D23113, https://doi.org/ 10.1029/2011JD016205.

—_ and H. Qian, 2016: Stratospheric temperature climate data record from merged SSU and AMSU-A observations. J. Atmos. Oceanic Technol., 33, 1967-1984, https://doi.org/ 10.1175/JTECH-D-16-0018.1.

, M. D. Goldberg, N. C. Grody, J. T. Sullivan, C. Cao, and D. Tarpley, 2006: Recalibration of Microwave Sounding Unit for climate studies using simultaneous nadir overpasses. J. Geophys. Res., 111, D19114, https://doi.org/ 10.1029/2005JD006798.

,-- , and X. Hao, 2018: New generation of U.S. satellite microwave sounder achieves high radiometric stability performance for reliable climate change detection. Sci. Adv., $\mathbf{4}$, eaau0049, https://doi.org/10.1126/sciadv.aau0049. 